\title{
Subsurface Fluid Injection and Induced Seismicity in Southeast Saskatchewan
}

James P. Verdon ${ }^{\mathrm{a}, b^{*}}$, J-Michael. Kendall ${ }^{\mathrm{a}, \mathrm{b}}$, Anna C. Horleston ${ }^{\mathrm{a}}$, Anna L. Stork $^{\mathrm{a}}$

a. School of Earth Sciences, University of Bristol, Wills Memorial Building, Queen's Road, Bristol, U.K., BS8 IRJ.

b. Outer Limits Geophysics LLP, 608 Malt House, East Tucker Street, Bristol, U.K., $B S 16 L Q$

* Corresponding Author. Email: James.Verdon@bristol.ac.uk, Tel: 0044117331 5135 .

Keywords: CCS, Induced Seismicity, Geomechanics, Saskatchewan 


\begin{abstract}
In order to mitigate $\mathrm{CO}_{2}$ emissions while continuing to use fossil fuels as an energy source, $\mathrm{CO}_{2}$ emissions from large point sources such as power stations can be captured and stored in suitable subsurface sedimentary formations. However, concerns have been raised that the injection of pressurized $\mathrm{CO}_{2}$ may alter the subsurface stress state, leading to the re-activation of faults and generating induced seismic activity. Southeast Saskatchewan has seen extensive oil and gas activity since the 1950s. This activity includes, in recent years, a boom in shale oil production entailing hydraulic fracturing. It is also home to two world-leading CCS projects, the Weyburn-Midale $\mathrm{CO}_{2}$ Monitoring and Storage Project, and the Boundary Dam/Aquistore Project. The aim of this paper is to assess whether any of the conventional oilfield operations, shale oil activity or CCS has caused induced seismicity in southeast Saskatchewan. We find that the region has a very low rate of natural seismicity, and that there is no evidence to suggest that any kind of oilfield activity has caused induced events. However, seismicity has been associated with potash mining activities in the region. It is not clear whether the potash mining-induced events are triggered by subsidence above the mined zones, or by re-injection of waste brines. It is of interest to compare the situation in southeast Saskatchewan with other areas that have seen substantial increases in the amount of injection-induced seismic activity. It is notable that in many areas that have seen injection-induced seismicity, fluid injection is into basal aquifers that are hydraulically connected to the crystalline Precambrian basement. In contrast, most oilfield activities in southeast Saskatchewan are in Carboniferous formations, while the only units to have experienced a net volume increase are of Cretaceous age. It is tentatively suggested that the lack of induced seismic activity is due to the fact that injection is hydraulically isolated from the basement rocks, although it is also possible that stress conditions in the region are less conducive to induced seismicity.
\end{abstract}




\section{INTRODUCTION}

It has been conclusively demonstrated that injecting fluids into the subsurface can trigger seismic activity (e.g., Raleigh et al., 1976). However, early research on Carbon Capture and Storage (CCS) was focussed on the danger that the buoyant $\mathrm{CO}_{2}$ plume will migrate through the caprock and leak back to the surface. The potential hazard posed by injection-induced seismicity was generally downplayed (e.g. Damen et al., 2006) or not considered (e.g. Bickle, 2009). Even where microseismicity was observed at CCS sites, such observations were generally considered in terms of potential leakage through the caprock because of fracturing, rather than the hazard posed by injection-induced seismicity (e.g., Verdon et al., 2011).

However, these assessments were made prior to recent events in the mid-continental USA, where sharp increases in wastewater disposal volumes have lead to a dramatic increase in the number of recorded earthquakes (Ellsworth, 2013). Given that, on a well-by-well basis, injection volumes proposed for future CCS sites match or even exceed current wastewater injection volumes (e.g. Verdon, 2014), these observations have lead to a re-appraisal of the hazard posed by injection-induced seismicity at CCS sites (e.g. Zoback and Gorelick, 2012).

The Williston Basin underlies parts of Saskatchewan, North and South Dakota, Montana and Manitoba. It is a large $\left(500,000 \mathrm{~km}^{2}\right)$ intra-cratonic basin of roughly oval shape, the origin of which is speculative. The Precambrian Trans-Hudson Orogen trends in a NE-SW direction beneath the basin, sandwiched between the Archaean Wyoming and Superior Cratons. The oldest formation to be deposited on top of Precambrian crystalline basement is the Deadwood Formation, which is of late Cambrian/early Ordovician age. At its deepest, the thickness of sediments above the Precambrian basement is about $5 \mathrm{~km}$. Most of the sediments are of Paleozoic age, although sedimentation continued through the Mesozoic. In Figure 1 we show a stratigraphic column and schematic cross section of the area.

Oil and gas has been extracted from fields in southeast Saskatchewan since the 1950s, and production continues today. Substantial volumes of produced water are also generated by this extraction. Some of this water is re-injected for secondary recovery, while some is disposed of into saline aquifers. Additionally, the Bakken Shale underlies the conventional fields in southeast Saskatchewan. Within the past decade, this resource has been targeted for shale oil extraction using hydraulic fracturing.

$\mathrm{CO}_{2}$ injection for the combined purposes of Enhanced Oil Recovery (EOR) and Carbon Capture and Storage (CCS) has been conducted at the Weyburn oilfield, in southeast Saskatchewan, since 2000. In 2015, $\mathrm{CO}_{2}$ injection for CCS began at the Boundary Dam/Aquistore site, near to Estevan (approximately $85 \mathrm{~km}$ southeast of Weyburn). Southeast Saskatchewan is therefore home to two world-leading CCS projects, which provide an 
excellent opportunity to study the effects of $\mathrm{CO}_{2}$ injection into the subsurface. At Weyburn, oil production is from, and $\mathrm{CO}_{2}$ injection is into, Carboniferous rocks at a depth of approximately $1.5 \mathrm{~km}$, while at Aquistore, $\mathrm{CO}_{2}$ is injected into the Deadwood Formation, which sits on top of the Precambrian basement at a depth of approximately $3.5 \mathrm{~km}$.

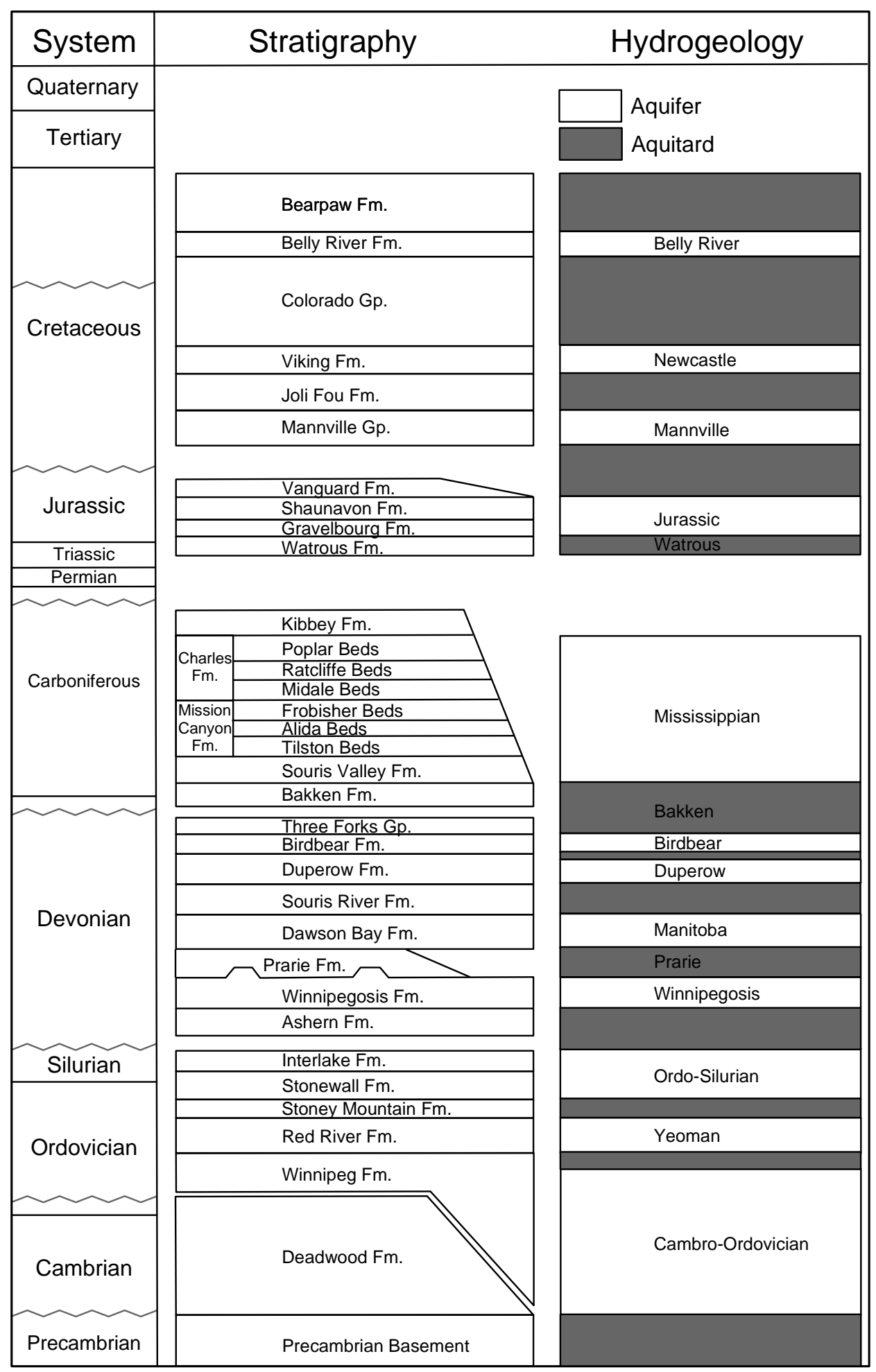

(a) 


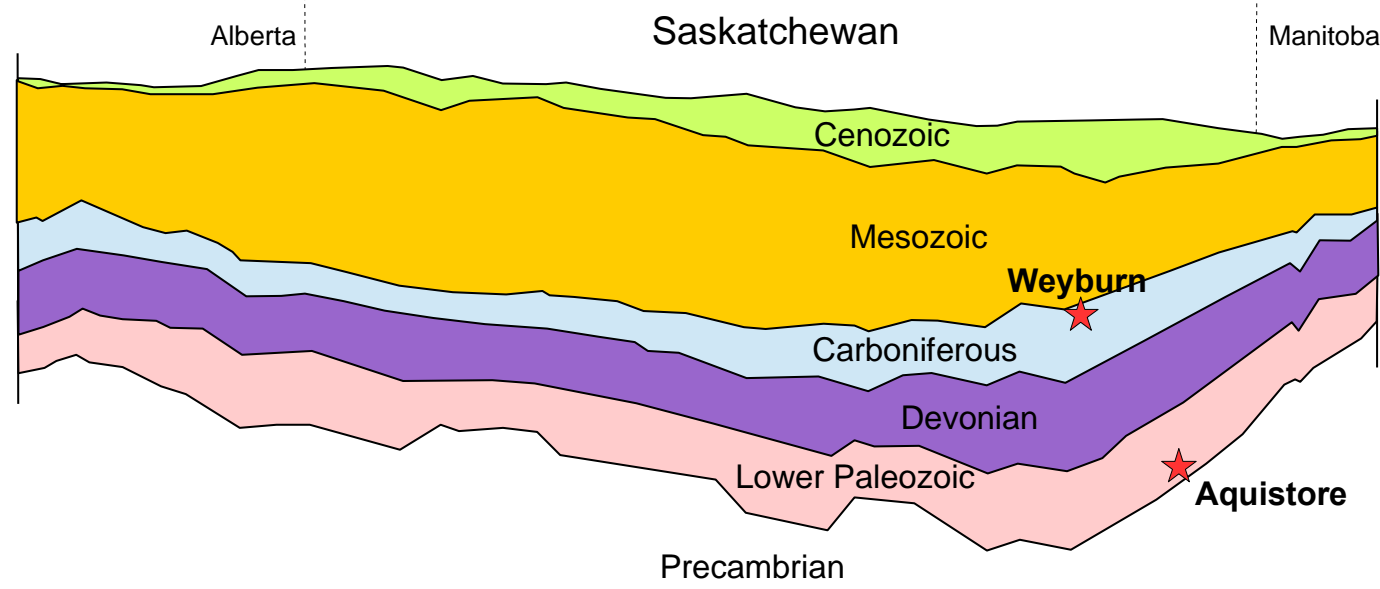

(b)

Figure 1: In (a) we show a stratigraphic column showing the key lithologies in our study area. Each stratigraphic unit is categorised as being either an aquifer, through which fluids can flow relatively easily, or an aquitard, through which fluid flow is difficult or impossible, owing to the unit's low permeability. In (b) we show a schematic cross section running from west to east through southern Saskatchewan. The approximate positions and target depths of the Weyburn oilfield and Aquistore CCS project are both marked. Both figures are modified from Rostron et al. (2012).

Therefore, there are and have been a range of oilfield activities conducted in southeast Saskatchewan that have the potential to induce seismic activity. The aim of this paper is to evaluate recorded seismicity in southeast Saskatchewan and to compare this activity with industrial activities in the area, thereby establishing whether oilfield activities have induced seismic activity. By doing so, we hope to better understand the tectonic setting in which these CCS sites are being developed, and thereby to assess the likelihood that they will lead to injection-induced seismicity as larger volumes of $\mathrm{CO}_{2}$ are injected. Our principal study area extends northwards from the USA-Canada border approximately $1^{\circ}$ of latitude $\left(49^{\circ}-50^{\circ} \mathrm{N}\right)$ and westward from the Saskatchewan-Manitoba border approximately $3.5^{\circ}$ of longitude $\left(101.4^{\circ}-105^{\circ} \mathrm{W}\right)$. However, we also consider seismic activity across the broader southeast Saskatchewan-Montana-North Dakota region, which covers much of the Williston Basin.

\section{SEISMICITY RECORDED IN SOUTHEAST SASKATCHEWAN}

\subsection{Monitoring Networks}

We begin by curating a catalogue of seismic events recorded in the southeast SaskatchewanMontana-North Dakota region. Broadly speaking, seismicity in this region is rare, and of low to moderate magnitude. However, for long periods, seismometer coverage has been equally 
sparse. Horner and Hasegawa (1978) describe the historical seismometer coverage in this area, and estimate detection thresholds of magnitude 6 prior to the 1950s, and of magnitude 5 until the mid-1960s. From this time onwards, detection thresholds are estimated to be magnitude 3, although the Large Aperture Seismic Array (LASA), which was deployed in Montana in 1966-67, provided a brief period of improved detection (Reinbold and Gillespie, 1974).

At present, several permanent stations of the USGS Advanced National Seismic System (ANSS) and Global Seismographic Network (GSN) provide the nearest real-time coverage. The nearest such station is at Dagmar, Montana (DGMT) which is approximately $130 \mathrm{~km}$ from the area of interest (Figure 2a).

However, several studies have shown that such regional networks may not be able to detect small injection-induced events (e.g., Frohlich, 2012; Friberg et al., 2014; Frohlich et al., 2015). Therefore, in addition to events listed in National Earthquake Information Centre (NEIC) and National Earthquake Database of Canada (NEDC) catalogues, we also identified additional seismometer networks with which to search for small events. These additional stations are shown in Figure 2b, and included:

- Stations of the Earthscope USArray Transportable Array that swept through Montana and North Dakota between from 2008 - 2011.

- In 2013, a network of 3 broadband seismometers were installed to monitor $\mathrm{CO}_{2}$ injection at the Aquistore project.

- Between August 2014 - August 2015, we installed an additional network of 3 seismometers to monitor the Weyburn CCS-EOR project.

With each of the above networks, we used an automated picking algorithm (Lomax et al., 2012) to search for potential events. Potential events were identified when at least 4 stations of the USArray, or all 3 stations of the Aquistore and Weyburn arrays, recorded co-incident triggers. 


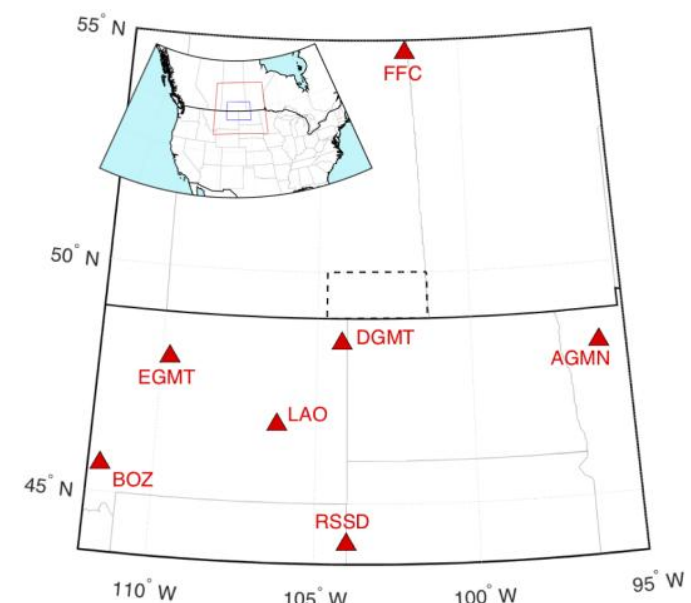

(a)

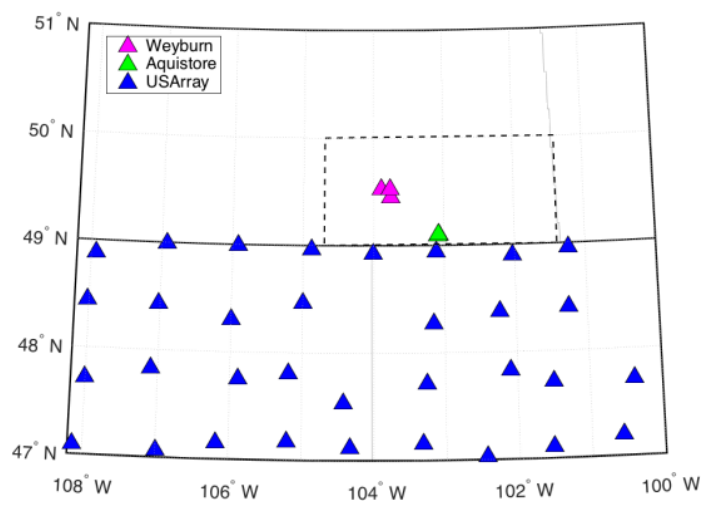

(b)

Figure 2: Monitoring stations used in this study. In (a), we show ANSS and GSN seismometers in the southeast Saskatchewan-Montana-North Dakota region. The inset shows the areas plotted in (a) (red rectangle) and (b) (blue rectangle). In (b), we show USArray stations that passed through Montana and North Dakota from 2008 - 2011 (blue), the 3 seismometers installed to monitor the Aquistore CCS project in 2013 (green) and the 3 seismometers installed to monitor the Weyburn oilfield (magenta). In both plots the dashed rectangle shows our specific area of interest, where CCS projects are active in southeast Saskatchewan.

These potential events were then examined manually. Triggers that did not have the characteristics of a local earthquake (near-vertical P-wave arrival, followed by S-wave arrival on horizontal components, and consistent move-out of arrival times across the array) were discarded. P- and S-wave arrival times were re-picked manually, and inverted for event hypocentres using the NonLinLoc package (Lomax et al., 2009), and a flat layered velocity model based on refraction surveys conducted by Morel-à-l'Huissier et al. (1987) and Hajnal et al. (1997). We note that many apparent "events" were located in close proximity to known quarries and opencast coalmines. These events were assumed to represent quarrying blasts, and were discarded from further analysis. Local magnitudes were computed using the scale defined by Nuttli (1973).

\subsection{Detected Events}

Within the southeast Saskatchewan-Montana-North Dakota region, a total of 65 events were listed on NEIC and NEDC catalogues. In addition, a further 28 events, not listed in NEIC/NEDC catalogues, were extracted from Bakun et al. (2011). Our analysis of additional stations revealed a further 6 events that had not been detected by NEIC/NEDC networks - all of these events were detected using the USArray stations, and no additional events were detected using the Aquistore and Weyburn arrays.

Figure 3a shows all events listed in the NEIC/NEDC catalogues and by Bakun et al. (2011). Figure $3 \mathrm{~b}$ shows the additional events detected using USArray stations. Of these 6 events, we 
note that Frohlich et al. (2015) also detected 4 of these events (2009-07-16, 2009-08-31, 2010-03-21, and 2010-06-11). Frohlich et al. (2015) detected a further 5 events that were not detected during our analysis. This is because Frohlich et al. (2015) had a different area of interest (Bakken Shale activities in Montana and North Dakota) and so included USArray stations further to the south in their analysis that we did not use. Our overall compiled catalogue is shown in Figure 4.

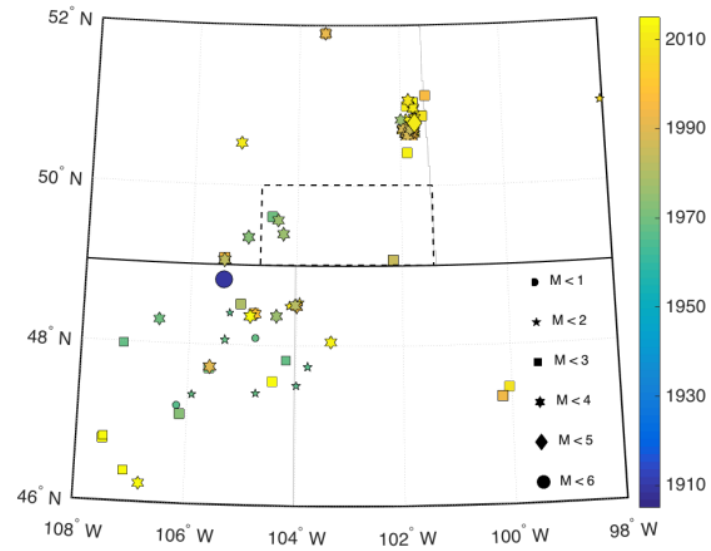

(a)

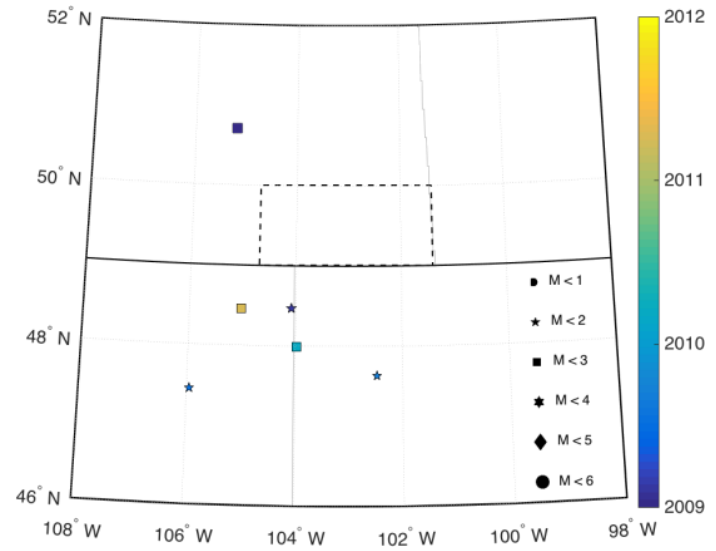

(b)

Figure 3: In (a) we show earthquakes listed in NEDC and NEIC catalogues, and in Bakun et al. (2011). In (b) we show additional events detected using USArray stations. Event symbols indicate magnitudes, and colours indicate the time of occurrence.

Figure 5 shows event magnitudes through time. The largest event in the region occurred in 1909, and is known as the Northern Great Plains Earthquake. Bakun et al. (2011) estimate a magnitude of 5.3 for this event, though for obvious reasons, both the hypocentre and the magnitude of this event are not well constrained. This event serves as an indication that, while events in this region are generally small, there must be faults present that are capable of generating larger events, and that this should be kept in mind when assessing the risks of injection-induced seismicity. However, since this event, no earthquake larger than magnitude 4.0 has been detected in the region. 


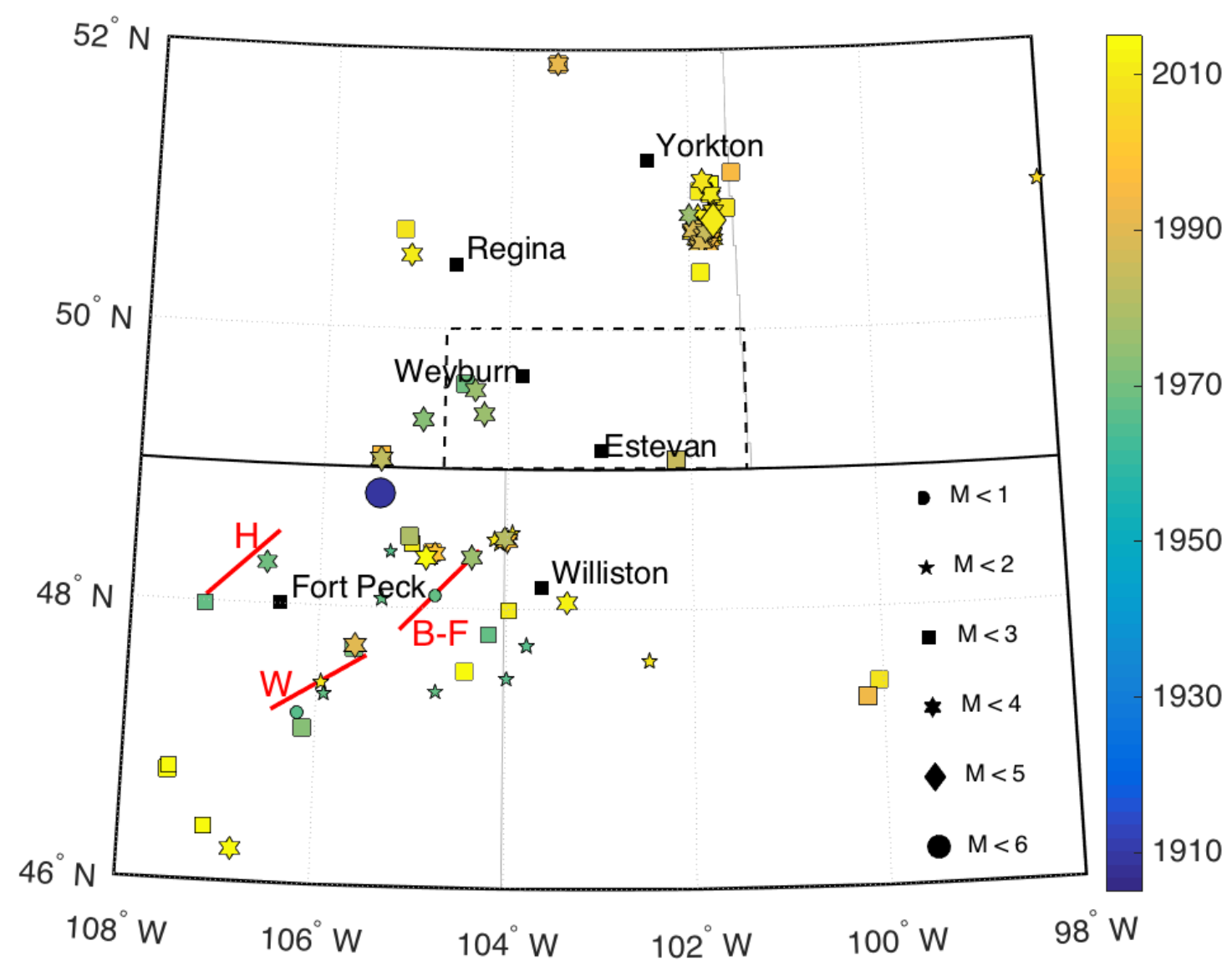

Figure 4: Compilation of all earthquakes recorded in the southeast Saskatchewan-Montana-North Dakota region. Event symbols indicate magnitudes, and colours indicate the time of occurrence. The mapped Hinton (H), Weldon (W) and Brockton-Froid $(B-F)$ fault traces are marked (based on Bakun et al., 2011).

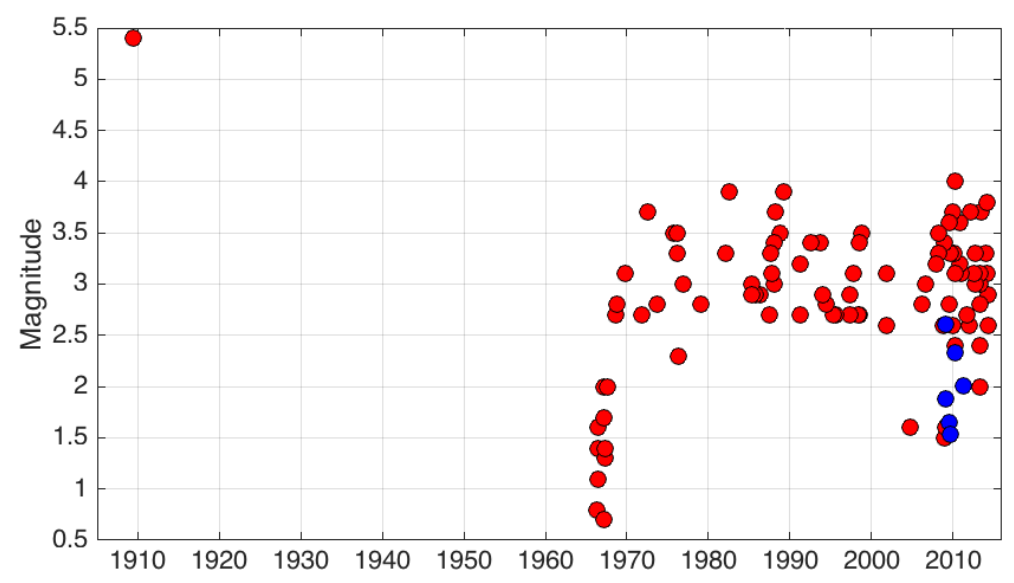

Figure 5: Event magnitude and occurrence times of all earthquakes in the southeast SaskatchewanMontana-North Dakota region. Red = catalogue events, blue = additional USArray events. The lowmagnitude events recorded in the late 1960s were detected using the LASA array.

We note a number of features in the overall event catalogue (Figures 4 and 5): 
- The large cluster of events to the southeast of Yorkton is associated with potash mining at the Mosaic Company (International Minerals and Chemical Corp as was) mine. Seismicity might be caused by either subsidence in the rocks overlying the mined zone, or by re-injection of waste brines into underlying rocks. Hasegawa et al. (1989) and Gendzwill and Unrau (1996) attribute the seismicity to subsidence above the mined zone.

- A further 2 events, to the NW of Regina are also located near to the Belle Plaine potash mine, and again are assumed to be caused by mining activities. These examples indicate that industrial activities, even if not oil and gas activities, are clearly capable of creating induced seismicity in the region.

- Most of the remaining events fall along a NE-SW trend extending from Montana into North Dakota and Saskatchewan. This trend matches the trend of 3 mapped faultzones, the Brockton-Froid, Hinsdale and Weldon (Figure 3 of Bakun et al., 2011). This trend also follows the strike of the Trans-Hudson Orogen through the region.

Horner and Hasegawa (1978) link naturally occurring seismicity in the region to both basement structures and to natural dissolution of the Paleozoic Prairie Evaporite deposits. The Prairie Evaporite deposit, of Middle Devonian age, is found in the sedimentary sequence across much of the region. It is more than $200 \mathrm{~m}$ thick in places, and lies at depths of between 400m - 3000m (Hasegawa et al., 1989). Wilson et al. (1963) suggest that basement lineaments lead to the localisation of upward fluid migration, which in turn results in the dissolution of the evaporites. Horner and Hasegawa (1978) argue that the salt dissolution produces stress changes that cause seismicity, pointing out that some of the recorded seismicity correlates with the edges of the Prairie Evaporite deposits, and with major salt dissolution structures.

Several events are located within the area that has seen a recent boom of activity in the Bakken Shale. Within this region, hydraulic fracturing is used to extract shale oil from the Bakken and Three Forks Formations, while produced water and wastewater from the hydraulic fracturing process are re-injected into saline aquifers (Gaswirth et al., 2013). Both processes have the potential to generate seismic activity. Frohlich et al. (2015) investigated these earthquakes, but were only able to tentatively link one event to injection and/or production activities. This was the $\mathrm{M}_{\mathrm{L}}=2.3$ event on 2010-03-21, where both production and injection wells were active within $5 \mathrm{~km}$ of the epicentre, and no prior events had been recorded in this vicinity. The remaining events do not occur in close proximity to active wells. Instead, these events occur in the same vicinity as previous earthquakes that have been associated with the Brockton-Froid fault zone (Figure 4) that occurred prior to the current boom in Bakken Shale activity. 
Finally, we note that, within the specific area of interest of our investigation, 4 events have been recorded, occurring in 1968, 1976, 1976, and 1985. Despite the extensive oilfield activity that has since been conducted in the area, no further events have been identified.

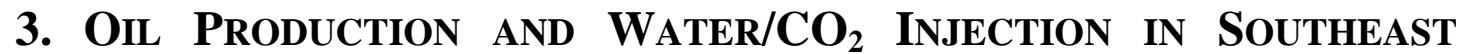

\section{SASKATCHEWAN}

Volumes of fluids produced and injected in Saskatchewan are reported to the Saskatchewan Ministry of the Economy, who provided the data used in this study. Data were provided on a well-by-well basis for over 25,000 wells, shown in Figure 6, for a period covering 2000-01 to 2014-12. Monthly volumes of oil and gas production, water production, water (re-)injection, and $\mathrm{CO}_{2}$ injection, were listed. Total injection and production volumes for the period $2000-$ 2014 are listed in Table 1. Overall, the volume of fluids produced slightly exceeds the volumes injected. However, we note that the volume of water produced far exceeds the volume of oil produced, and that this water is almost entirely re-injected. In Figure 7 we plot the cumulative fluid volumes through time.

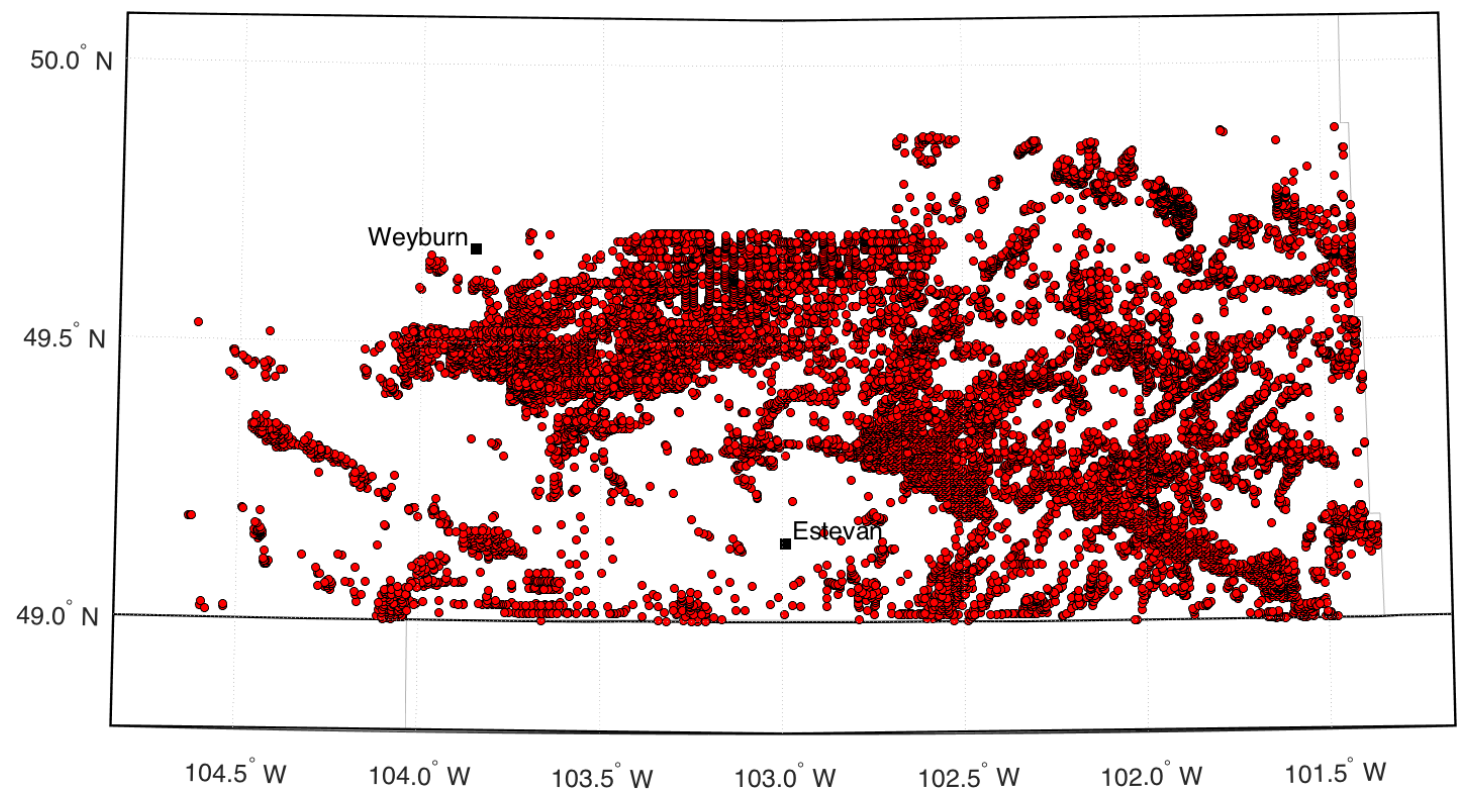

Figure 6: Locations of all production and injection wells provided by Saskatchewan Ministry of the Economy and used in this study.

\begin{tabular}{cc}
\hline Fluid & Volume $\left(\boldsymbol{m}^{3}\right)$ \\
\hline Oil Produced & $1.39 \times 10^{8}$ \\
Water Produced & $1.95 \times 10^{9}$ \\
All Fluids Produced & $2.09 \times 10^{9}$ \\
Water Injected & $1.96 \times 10^{9}$ \\
$\mathrm{CO}_{2}$ Injected & $4.70 \times 10^{4}$ \\
Net Fluid Produced - Injected & $1.33 \times 10^{8}$ \\
\hline
\end{tabular}

Table 1: Total volumes of fluids produced from and injected into oilfields in southeast Saskatchewan. Note that $\mathrm{CO}_{2}$ injection volumes are listed by the Saskatchewan Ministry of the Economy are in units of 
standard $\mathrm{m}^{3}$. We assume a density of $700 \mathrm{~kg} / \mathrm{m}^{3}$ to convert $\mathrm{CO}_{2}$ volumes at standard conditions into volumes at reservoir conditions, which is an approximation for $\mathrm{CO}_{2}$ density at the pressure and temperature conditions of the Weyburn oilfield.

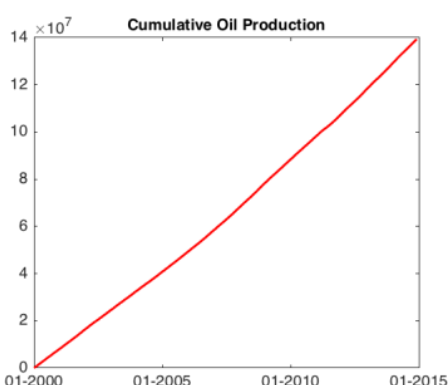

(a)

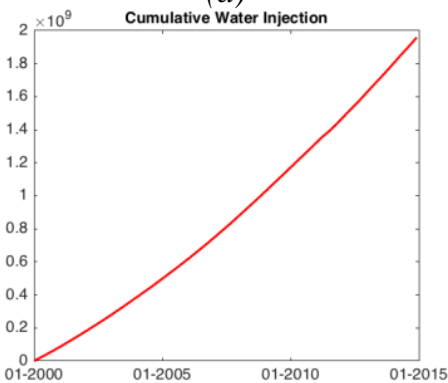

(d)

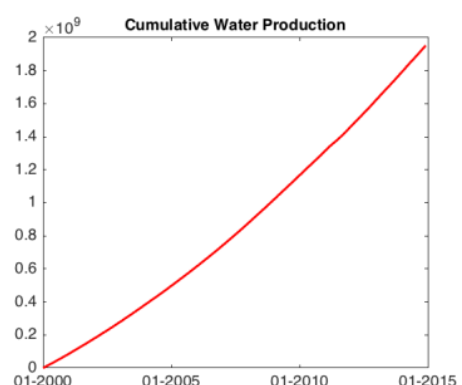

(b)

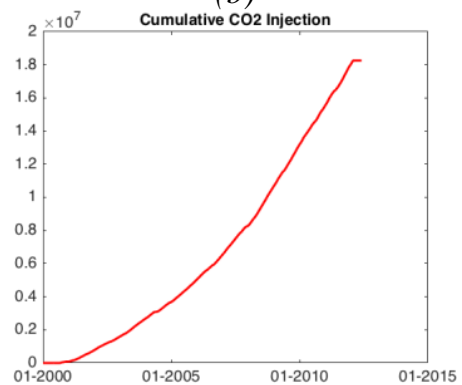

(e)

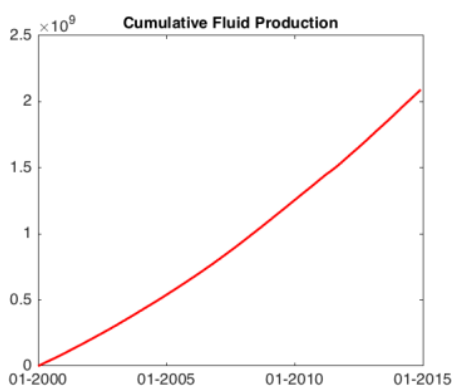

(c)

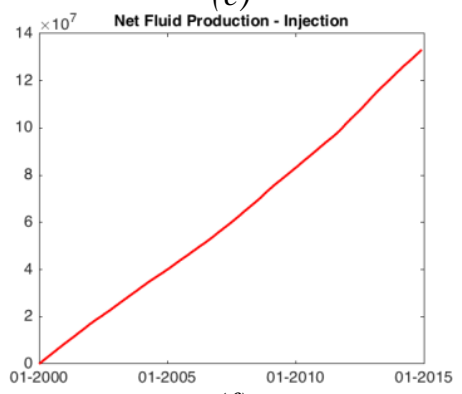

$(f)$

Figure 7: Cumulative fluid production and injection volumes (in $\mathrm{m}^{3}$, excepting $\mathrm{CO}_{2}$ volumes, which are standard $m^{3}$ ) from 2010 to 2015.

Although the net volume change is negative (i.e., more fluid is produced than is injected), there may be areas and/or units where injection volumes exceed production, and which would therefore potentially be more prone to seismicity. Therefore, in Figure 8 we divide the study area into blocks, and consider injection and production volumes within these blocks. We note that in most blocks, production exceeds injection. However, there are areas where injection volumes do exceed production volumes. Seismicity associated with oilfield activities can be induced by both fluid injection and production (e.g. Frohlich and Brunt, 2013). However, it is generally accepted that increases in pore fluid volumes (and therefore pore pressures) associated with fluid injection are the more common cause of induced seismicity. Therefore we expect areas and/or units experiencing a net volume increase to be most prone to induced seismicity. 


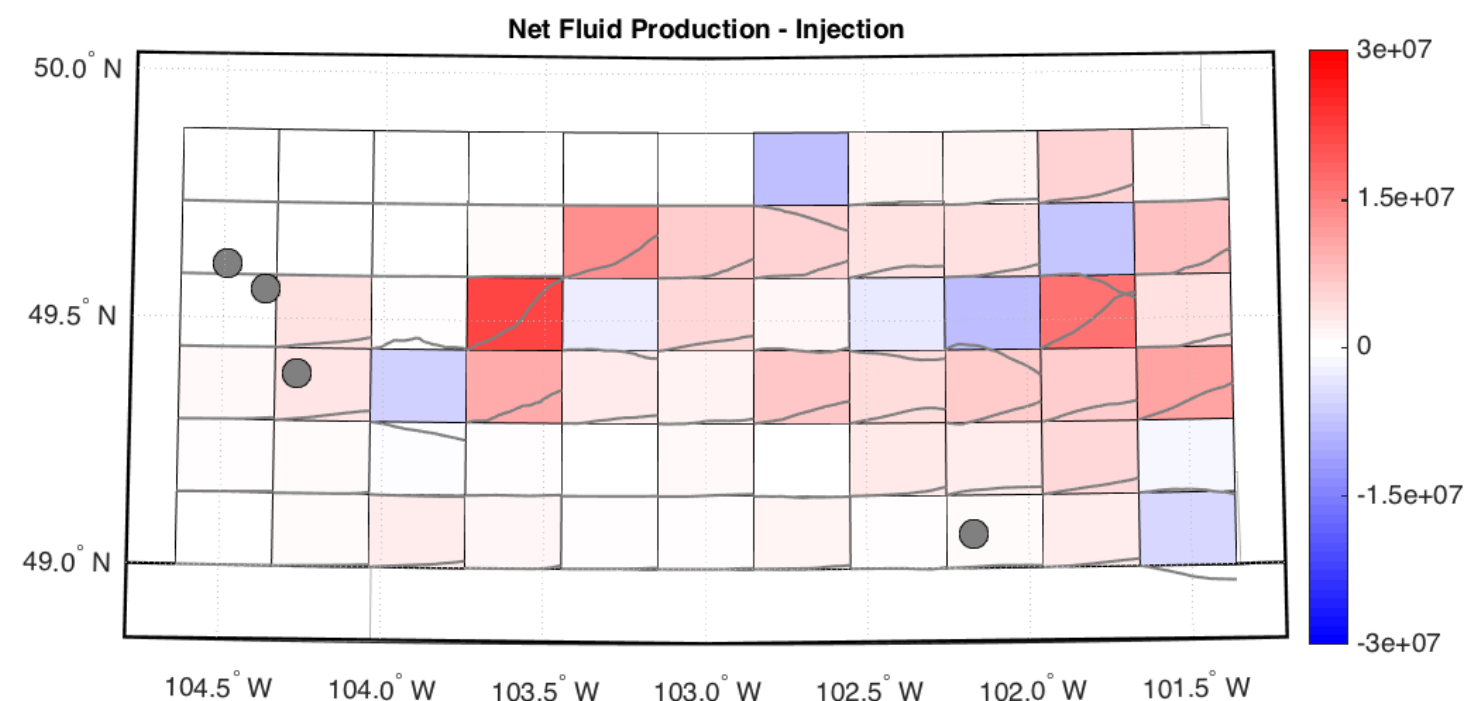

Figure 8: Spatial variations in net fluid produced - fluid injected across the area of interest. Each block is coloured by net fluid produced - injected (in $\left.\mathrm{m}^{3}\right)$. Blue values indicate produced - injected is negative (i.e. more fluid is injected than produced). The grey lines indicate relative rates through time, where the left edge of each block is 2000, and the right hand edge is 2015. The 4 earthquakes within the study area are also shown as grey dots.

Fluids are produced from and injected into different geological units within this area. The geological ages of formations targeted by injection and production wells are listed in the well data provided by Saskatchewan Ministry of the Economy. In Figure 9 we plot fluid volumes by the age of the geological formation. The majority of oil production and water injection occurs in Carboniferous units. However, significant volumes of water are also re-injected into shallower Cretaceous units.

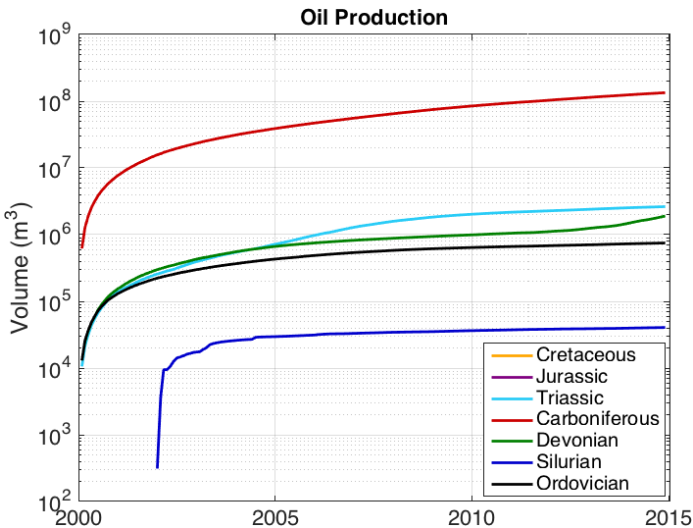

(a)

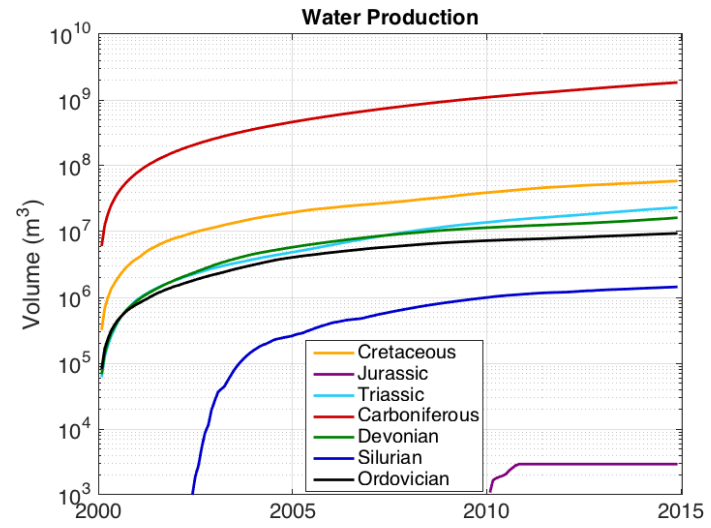

(b) 

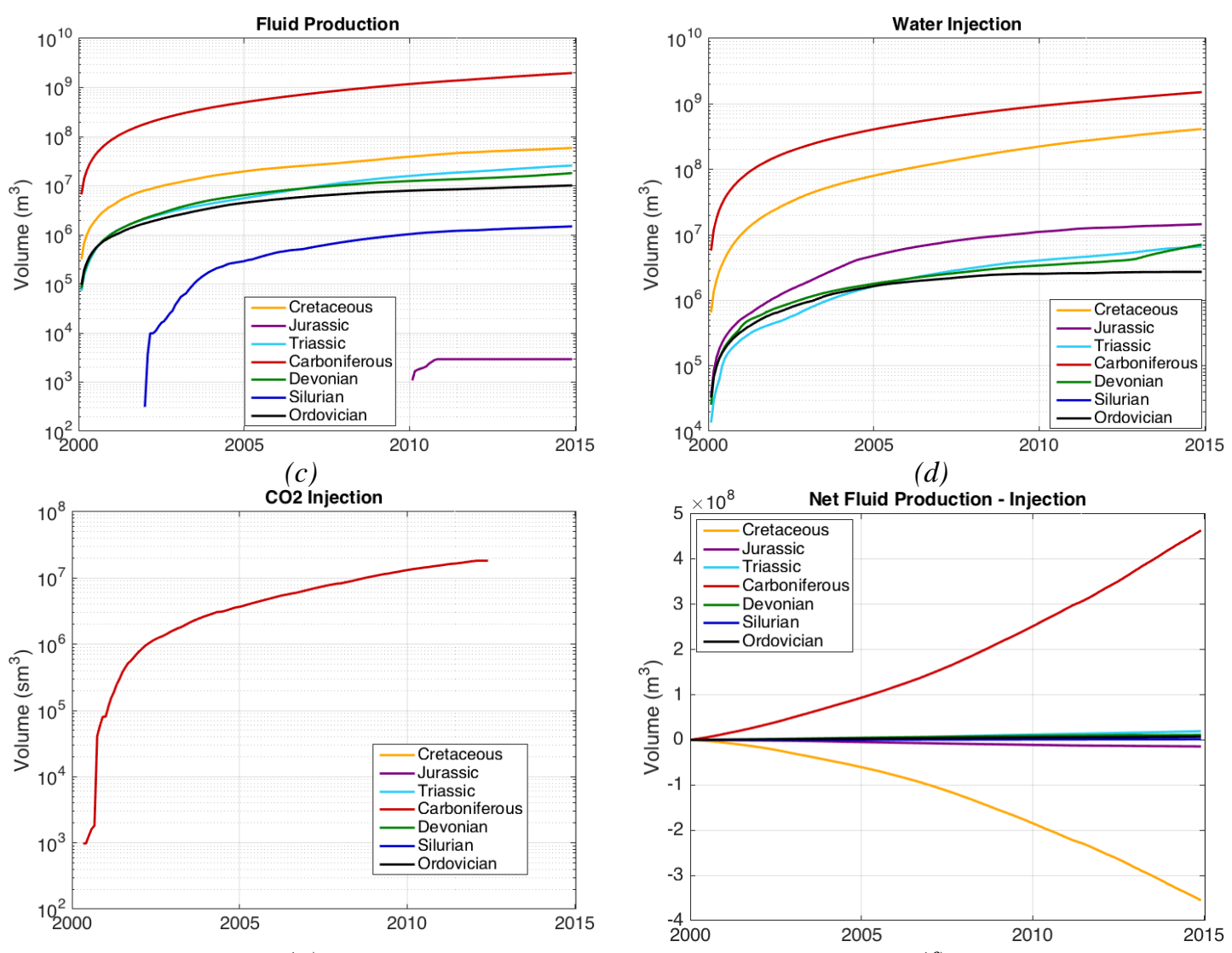

(e)

$(f)$

Figure 9: Cumulative fluid production and injection volumes from 2010 to 2015, as a function of the geological age of the unit from/into which fluid is produced/injected. The y-axes of panels (a) - (e) are logarithmic to allow the differing volumes to be viewed clearly. Where no production/injection has taken place from/into a unit, no line is plotted.

Verdon (2014) noted that in many (though not all) cases, injection-induced seismicity occurs when fluids are injected into layers near to the crystalline basement. This suggests that injection in basal layers may be of greater concern than in shallower layers that are hydraulically isolated from basement rocks. For example, much of the wastewater disposal being conducted in Oklahoma, which has seen a substantial increase in injection-induced seismicity, is injected into the Arbuckle Formation, which overlies crystalline basement rocks (Keranen et al., 2013; 2014). Three cases of injection-induced seismicity in Ohio, at Perry (Nicholson et al., 1988), at Ashtabula (Seeber et al., 2004) and Youngstown (Kim, 2013) all involved injection into the Mt Simon Formation, which again overlies crystalline basement rocks. Similarly, injection wells that triggered seismicity in Arkansas were injecting into the Ozark aquifer, which in that location has a direct hydraulic connection to underlying basement rocks (Horton, 2012).

In contrast, in southeast Saskatchewan, volume changes in deep basal layers are small, with most oilfield activity focussed in Carboniferous and Mesozoic layers. The only units experiencing a substantial net volume increase are of Cretaceous age, which are unlikely to 
have any hydraulic connection to the basement rocks. It is possible that the absence of a hydraulic connection between layers in the basement and the layers with net volume increases is the reason for the lack of induced seismicity in this area.

\section{Correlation Between Oilfield ACtivities ANd Seismicity?}

Figure 8 shows the epicentres of the 4 events that have occurred within our study area, overlain on a map showing areal variations of net fluid injection volumes. Figure 8 should not be used as a direct comparison between seismicity and injection, because the injection data is from 2000 onwards, a long time after these events occurred. However, assuming that injection and production activities have not changed location substantially, there is no obvious correlation between event locations and areas with larger volume changes (either positive or negative). Events are often deemed to be associated with a well if they occur within $5 \mathrm{~km}$ (Davis and Frohlich, 1993). In Figure 10 we overlay the event epicentres on a plot showing the distance to the nearest well (considering only wells that were drilled before 1985, when the last of these 4 events occurred).

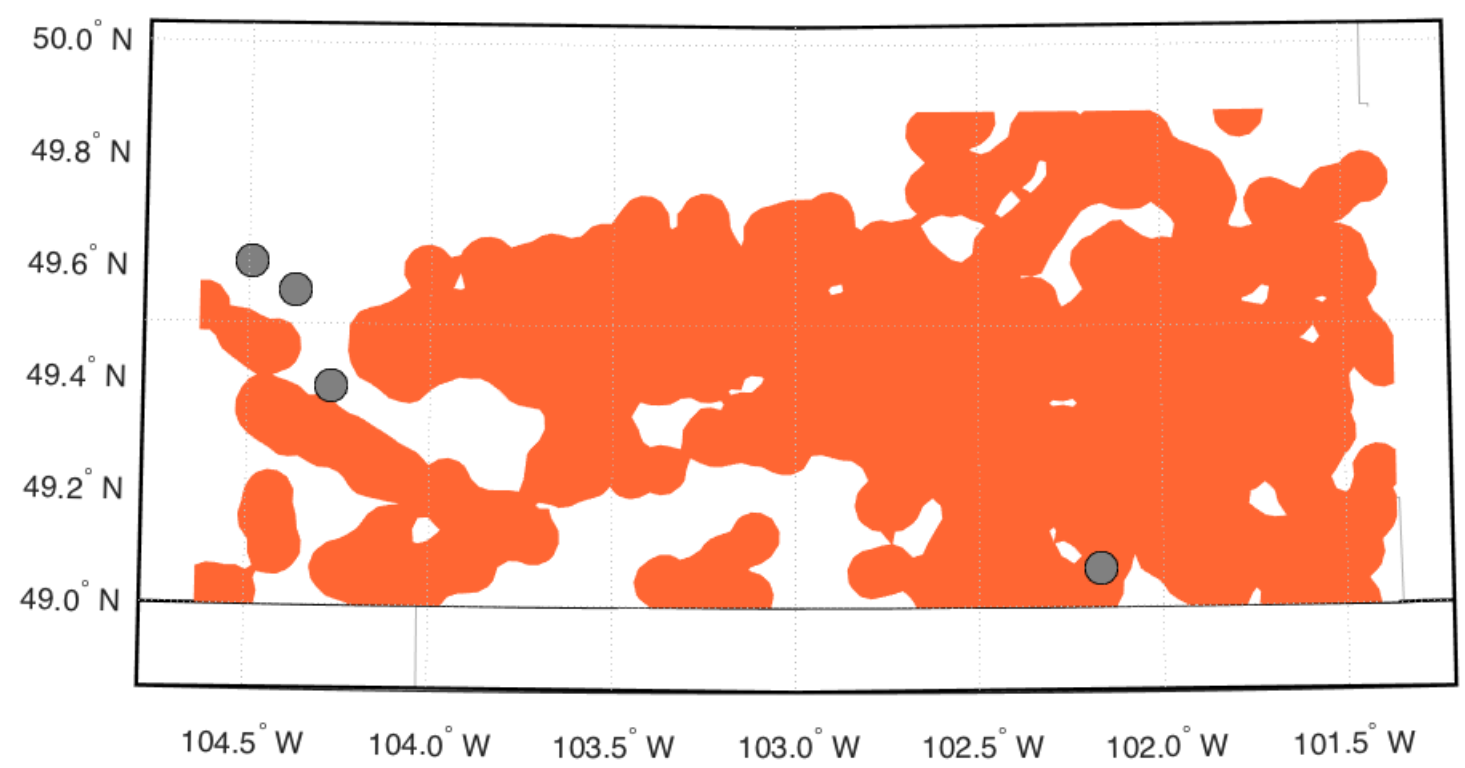

Figure 10: Epicentres of the 4 events located within the study area (grey dots), overlain on a map showing localities - shaded areas - that are within $5 \mathrm{~km}$ of a well (either injection or production) active in 1985 (the date of the last event to occur in the area). Much of the study area is within $5 \mathrm{~km}$ of at least one well. Nevertheless, 3 of the 4 events are located more than $5 \mathrm{~km}$ from any well.

In order to assess the possibility that events have been induced by industrial activities, we consider them within the framework for induced seismicity outlined by Davis and Frohlich (1993). A series of questions are posed, where predominately "yes" answers indicate that an event may have been induced by industrial activities. The questions, and their answers in this particular case, are: 
1. Are the events the first known earthquakes of this character in the region?

Hydrocarbon production in this area commenced in the 1950s. However, adequate seismometer coverage was only achieved in the 1960s. Therefore, we have no assessment of seismicity rates prior to oilfield activities with which we can answer this question robustly. However, the rate, magnitudes and positions of these events suggest that they are a continuation of the trend of seismicity running NE from Montana. This overall trend in seismicity is seen in producing and non-producing areas alike, suggesting that these events represent a natural trend.

\section{Is there clear temporal correlation between injection and seismicity?}

Injection and production has continued apace for nearly 30 years since the last event within the study area. There does not therefore appear to be any temporal correlation between injection and seismicity

\section{Are epicentres near to wells (within $5 \mathrm{~km}$ )?}

When considering only wells that were active when these events happened, only one event is (just) within $5 \mathrm{~km}$. However, there is no spatial correlation between seismicity and injection and/or production volumes.

\section{Do some events occur at or near to injection depths?}

Because of the lack of monitoring stations in the area, event depths are unconstrained. It is therefore not possible to answer this question.

\section{Are changes in fluid pressure sufficient to encourage seismicity?}

It is difficult to answer this question, since to model the pressure changes induced at each injection well is beyond the scope of this study. However, we can consider the case of Weyburn (as described in Verdon et al., 2011), one of the largest oilfields in the region, as a representative case. Oil has been produced at Weyburn from Carboniferous age formations since the 1950s, with water re-injection for secondary recovery. Tertiary recovery was initiated in 2000 with the injection of $\mathrm{CO}_{2}$ with the combined purpose of $\mathrm{CO}_{2}$ storage and EOR.

Jimenez Gomez (2006) conducted an extensive study of the geomechanical conditions at Weyburn. Based on prior studies of borehole breakouts, natural fractures and inelastic strain recovery tests (McLennan et al., 1986; McLellan et al., 1992), Jimenez Gomez (2006) reports a maximum horizontal stress azimuth of $40-50^{\circ}$, a vertical stress gradient of $24 \mathrm{kPa} / \mathrm{m}$ and a minimum horizontal stress gradient of $18 \mathrm{kPa} / \mathrm{m}$. Jimenez Gomez reports a maximum horizontal stress gradient of $28 \mathrm{kPa} / \mathrm{m}$, although this is not well constrained, and he suggests a 
more realistic value to be $26 \mathrm{kPa} / \mathrm{m}$. Stress orientations can also be determined from measurements of seismic anisotropy, where the fast shear wave polarisation is typically found to be parallel to the $S_{H}$ direction (Boness and Zoback, 2006). Using both shear wave splitting measurements made on microseismic data (Verdon et al., 2011) and controlled source AVOA observations (Duxbury et al., 2012), the anisotropic fast axis at Weyburn appears to be oriented at an azimuth of $45^{\circ}$, which is in agreement with the orientation reported by Jimenez Gomez (2006).

Based on the above, we take the initial stress conditions at Weyburn, which is at a depth of approximately $1,450 \mathrm{~m}$, to be: $\mathrm{S}_{\mathrm{H}}=37 \mathrm{MPa}, \mathrm{S}_{\mathrm{h}}=26 \mathrm{MPa}, \mathrm{S}_{\mathrm{V}}=35 \mathrm{MPa}$, with a principal horizontal stress azimuth of $45^{\circ}$. Hydrostatic pore pressure at these depths is $14.5 \mathrm{MPa}$. We can resolve this stress tensor onto fault planes of arbitrary angle, computing normal stress, $\sigma_{n}$, and shear stress, $\tau$, for all possible fault planes. Mohr-Coulomb theory states that a fault plane will reactivate if

$$
\tau-\varphi \sigma_{n}-C>0
$$

where $\varphi$ is the friction coefficient, and $C$ is the cohesion. Faults are therefore most likely to be reactivated if they have strike and dip such that $\tau-\varphi \sigma_{n}$ is maximized. In Figure 11 we plot $\tau-$ $\varphi \sigma_{n}$ as a function of fault-normal azimuth and inclination, noting that this analysis suggests that faults striking ENE-WSW and NNE-SSW are most likely to be re-activated.

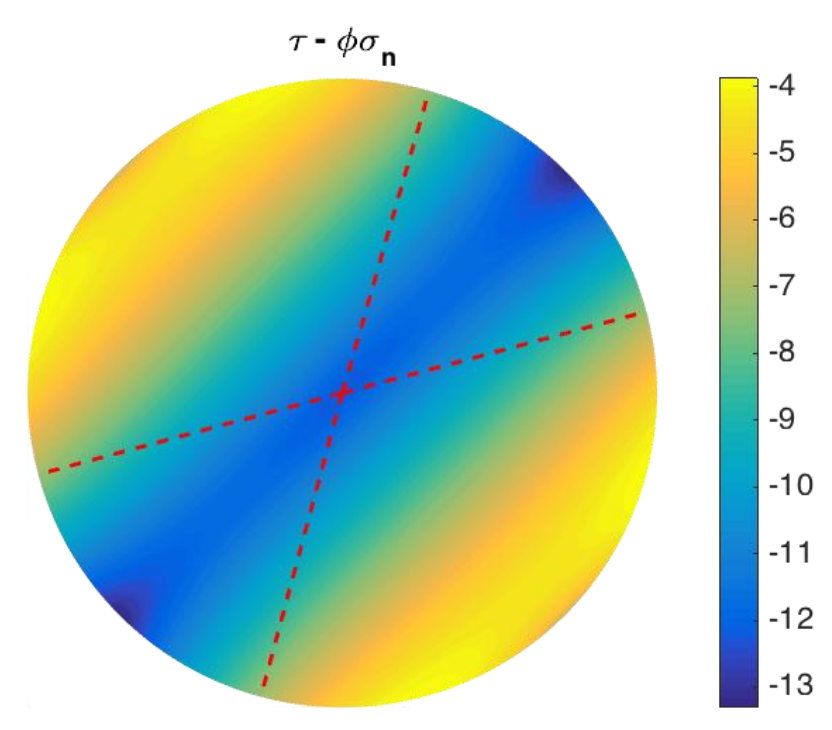

Figure 11: Stereoplots showing the Mohr-Coulomb criteria $\tau-\varphi \sigma_{n}$ as a function of fault-normal (i.e. the line drawn perpendicular to the fault plane) azimuth and inclination. Faults will be prone to failure when $\tau-\varphi \sigma_{n}$ is maximized. In this case, vertical faults striking NNE and ENE (marked by dashed red lines) will be most prone to failure. Vertical faults striking SE-NW will be least prone to failure. 
A pore pressure increase will reduce the effective normal stresses, increasing the probability of slip on a well-oriented fault. The effective stress, $\sigma_{i j}{ }_{i j}$, is determined as a function of the stress tensor applied to the rock, $\sigma_{i j}$, and the pore pressure, $P$ :

$$
\sigma^{\prime}{ }_{i j}=\sigma_{i j}-\beta_{w} I_{i j} P
$$

where $I_{i j}$ is a $3 \times 3$ identity matrix, and $\beta_{w}$ is the Biot-Willis parameter (e.g., Mavko et al., 1992), typically assumed to be 1 . However, as well as influencing the effective stress via the ' $P$ ' term in the above equation, pore pressure changes also affect the effective stress by causing a change in the applied stress. For an isotropic, porous elastic reservoir that is thin but laterally extensive, the change in horizontal applied stress as a function of a change in pore fluid pressure is

$$
\gamma_{H}=1-2 v / 1-v
$$

where $\square v$ is the Poisson's ratio, and $\gamma_{H}$ describes how much horizontal stress change $\Delta \sigma_{H}$ is caused by a pore pressure change $\Delta P$ :

$$
\gamma_{H}=\Delta \sigma_{H} / \Delta P \text {. }
$$

Assuming a typical value of $v=0.25$, Figure 12 shows how the Mohr circle, representing the stress conditions, moves as pore pressure increases. Also shown is a typical M-C failure envelope with a friction coefficient of 0.6. Slip can occur when the Mohr circle exceeds the failure limit. We find that a pore pressure increase of approximately $10 \mathrm{MPa}$ is sufficient to move the stress conditions from their current stable conditions and into a state where faults may be able to slip. This value matches the value found for the same conditions by Jimenez Gomez (2006), though we note that his thesis explored a much greater range of scenarios.

Various reservoir models have been created to simulate the change in pore fluid pressure during the various stages of production at Weyburn (e.g., Jimenez Gomez, 2006; Verdon et al., 2013). In the model used by Verdon et al. (2013), at no point does the pore pressure exceed 10MPa above hydrostatic. In the model used by Jimenez Gomez (2006), pressures do occasionally exceed 10MPa above hydrostatic, but only rarely and in isolated model cells, rather than systematically across the reservoir (Figures 8-6, 8-14 and B-19 - B-24 of Jimenez Gomez, 2006). In summary, while we cannot account for every injection well in the area of study, injection pressures within the one of the largest oilfields in the area have not reached the levels necessary to move faults in the present-day ambient stress field beyond the MohrCoulomb stability envelope. However, future plans for the Weyburn field include its conversion into a purely CCS site, once oil production is exhausted. This would entail continued $\mathrm{CO}_{2}$ injection without any fluid removal (Sun et al., this issue). In such a scenario, fluid pressures quickly increase to levels that are capable of moving faults beyond the Mohr- 
Coulomb stability envelope. We therefore recommend that if such plans are realized, extensive geomechanical and microseismic monitoring should be deployed to ensure that the risks entailed by deformation and fault re-activation can be mitigated (as described by Verdon et al., 2015).

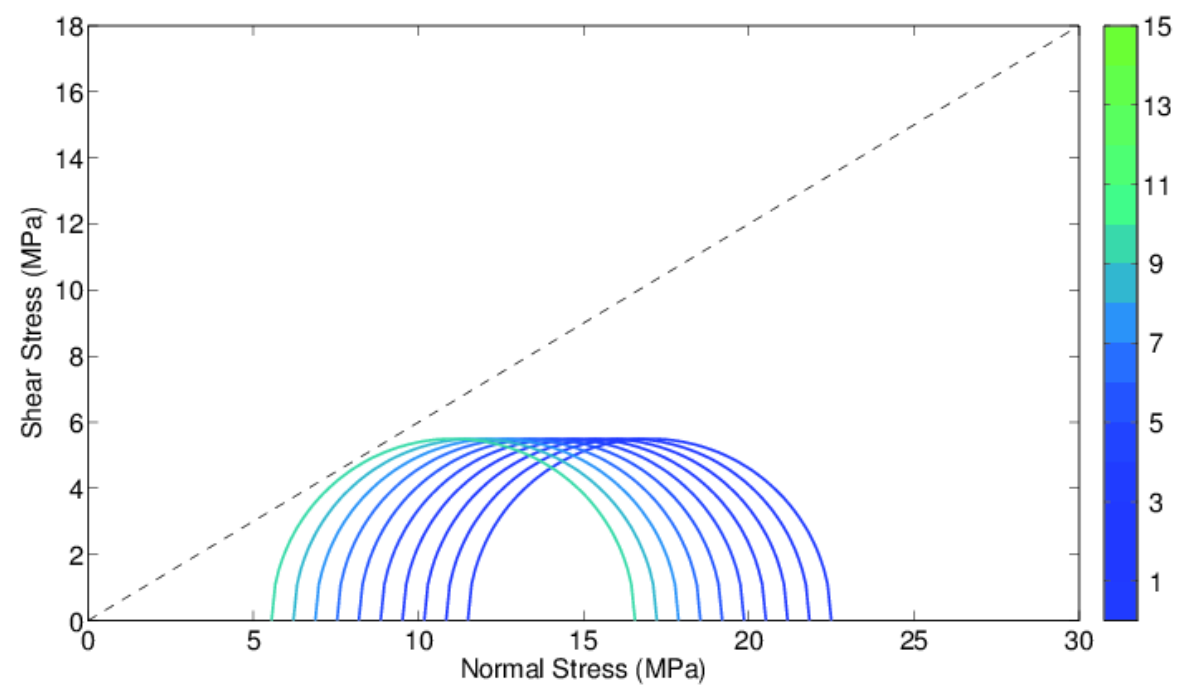

Figure 12: Mohr circles for Weyburn stress conditions as a function of pore pressure increase. Each Mohr circle represents the effective stress conditions for a given pore pressure increase from hydrostatic, denoted by the color. Each circle represents a IMPa increase in pore pressure. Also shown is a typical M-C failure envelope with a friction coefficient of 0.6: slip is likely if the Mohr circles exceed this envelope. A pore pressure increase of $10 \mathrm{MPa}$ is sufficient to move the Mohr circle from its initial conditions to reach the failure envelope.

\section{DISCUSSION}

Based on our observations and the questions discussed in the previous section, we conclude that there is no evidence to suggest that oilfield activities in southeast Saskatchewan have induced seismic activity. Broadly speaking, this conclusion applies across the Western Canadian Sedimentary Basin in general (Ferguson, 2015). However, it is worth comparing our study area with others that have experienced much higher levels of induced seismicity from similar levels of oilfield activity. By making this comparison, it may be possible to identify why seismicity occurs in some cases and not others, and thereby take steps towards mitigating the issue.

Frohlich (2012) and Keranen et al. (2014) both link induced seismicity in the mid-continental USA to the presence of high-volume wastewater disposal wells with monthly volumes in excess of 150,000 - 400,000 barrels per month (bbls/m). In Figure 13 we compare the 
maximum monthly injection rates in 2014 for wells in southeast Saskatchewan with data from Oklahoma ${ }^{1}$.

In Figure 13 we normalize the number of wells with a given injection volume by the size of the study area, such that we plot the number of wells with a given maximum injection rate per $100 \mathrm{~km}^{2}$. For Oklahoma, the area we use for this normalization is the area of the state. However, injection wells in Oklahoma are not evenly distributed, so it is likely that there are areas where the number of injection wells per unit area is larger than that plotted in Figure 13. Nevertheless, from Figure 13 it is apparent that there are similar numbers of injection wells with large monthly rates in both Oklahoma and southeast Saskatchewan. Therefore differences in injection volume alone cannot account for the differences in injection-induced seismicity.

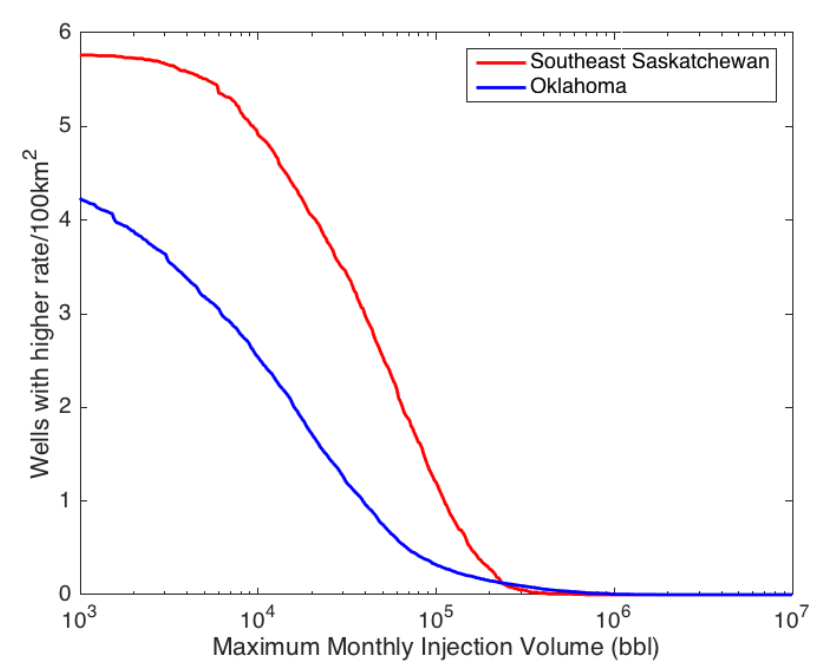

Figure 13: Cumulative distribution of the highest monthly injection rates for wells in southeast Saskatchewan (red), compared with wells in Oklahoma (blue), normalized by the sizes of the areas under consideration.

It is possible that the stress conditions in southeast Saskatchewan are such that faults are less likely to rupture. Williams-Stroud and Billingsley (2010) report a low level of stress anisotropy during hydraulic fracturing in the Bakken Shale, for example. This is consistent with the generally low levels of natural seismicity in the area. However, potash mining in southeast Saskatchewan has induced a substantial number of earthquakes, indicating that the stress conditions are such that seismicity can be triggered in this region, if the necessary forcing is applied.

Because they have not been well studied, it is not known whether these events are caused by subsidence of rocks overlying the mined zone, or by wastewater disposal in deeper layers.

\footnotetext{
${ }^{1}$ Injection well data for Oklahoma is available from: http://www.occeweb.com/og/ogdatafiles2.htm
} 
Further analysis of these events is needed to establish why potash mining in the region is able to induce seismicity, while oilfield activities have not.

A significant difference between the two regions is the injection depth. Wastewater disposal wells in Oklahoma, Ohio, and Arkansas, which have induced seismicity, inject into basal aquifers that are hydraulically connected to underlying crystalline basement rocks. In contrast, the only geological units to have experienced a net volume increase in southeast Saskatchewan are Cretaceous in age, and so are unlikely to have any hydraulic connection to the crystalline basement. Basement rocks generally have higher shear moduli and shear strength. This allows them to store higher shear stresses, and when ruptures occur, they will be more energetic (e.g., Vilarrasa and Carrera, 2015). Additionally, faults in basement layers cannot be easily mapped with reflection seismic surveys (and they are rarely the target for such surveys anyway, since they do not contain hydrocarbons). As such, basement faults may be present near to injection wells that are not detected. It might therefore be expected that injection into basal layers, with the result that pore pressures also increase in the crystalline basement, is more likely to lead to injection-induced seismicity.

Taking the above into account, we note that injection into basal layers is not a necessary condition for induced seismicity (e.g., Zoback and Gorelick, 2015). For example, injection wells in the Raton Basin that are $2-3 \mathrm{~km}$ above the basement have induced seismic activity (Rubinstein et al., 2014). Similarly, some injection wells in East Texas that are a substantial distance above the basement have also induced seismic activity (e.g., Justinic et al., 2013), while $\mathrm{CO}_{2}$ injection at In Salah, which is also well above the basement, has also produced seismicity (Stork et al., 2015).

To date, few wells have targeted the basal formations in southeast Saskatchewan. However, the Aquistore CCS pilot project has begun to inject $\mathrm{CO}_{2}$ into the basal Deadwood Formation. At present, only a small volume of $\mathrm{CO}_{2}$ has been injected, and no seismicity has been recorded. It will be of interest to see whether continued injection into this layer begins to trigger seismicity, as $\mathrm{CO}_{2}$ injection into the basal Mt Simon Formation has done at the Decatur CCS pilot project, Illinois (Kaven et al., 2015). The operators of the Aquistore project have installed an extensive passive seismic monitoring system (Worth et al., 2014). Whether or not seismicity is triggered may indicate whether injection into basal layers is a particular risk factor for injection-induced seismicity.

\section{Acknowledgements}

We would like to thank the US Department of Energy, and the Petroleum Technology Research Centre of Canada, for funding this research. We also thank Gavin Jensen from the Saskatchewan Ministry of the Economy for providing the fluid volumes for southeast 
Saskatchewan. Michael Kendall's Professorship and James Verdon's Research Fellowship at the University of Bristol are supported by the British Geological Survey.

\section{References}

Allen R.V., 1978. Automatic earthquake recognition and timing from single traces: Bulletin of the Seismological Society of America 68, 1521-1532.

Bakun W.H., Stickney M.C., Rogers G.C., 2011. The 16 May 1909 Northern Great Plains Earthquake: Bulletin of the Seismological Society of America 101, 3065-3071.

Bickle M.J., 2009. Geological carbon storage: Nature Geoscience 2, 815-818.

Boness N.L. and Zoback M.D., 2006. Mapping stress and structurally controlled crustal shear velocity anisotropy in California: Geology 34, 825-828.

Damen K., Faaij A., Turkenburg W., 2006. Health, safety and environmental risks of underground $\mathrm{CO}_{2}$ storage - overview of mechanisms and current knowledge: Climatic Change 74, 289-318.

Davis S.D., and Frohlich C., 1993. Did (or will) fluid injection cause earthquakes? - Criteria for a rational assessment: Seismological Research Letters 64, 207-224.

Duxbury A., White D., Samson C., Hall S.A., Wookey J., Kendall J-M., 2012. Fracture mapping using seismic amplitude variation with offset and azimuth analysis at the Weyburn $\mathrm{CO}_{2}$ storage site: Geophysics 77, N17-N28.

Ellsworth W.L., 2013. Injection-induced earthquakes: Science 341, 1225942.

Ferguson G., 2015. Deep injection of waste water in the Western Canada sedimentary basin: Groundwater 53, 187-194.

Friberg P.A., Besana-Ostman G.M., Dricker I., 2014. Characterization of an earthquake sequence triggered by hydraulic fracturing in Harrison County, Ohio: Seismological Research Letters 85, 1295-1307.

Frohlich C., 2012. Two-year survey comparing earthquake activity and injection-well locations in the Barnett Shale, Texas: Proceedings of the National Academy of Sciences 109, 13934-13938.

Frohlich C. and Brunt M. 2013. Two-year survey of earthquakes and injection/production wells in the Eagle Ford Shale, Texas, prior to the $\mathrm{M}_{\mathrm{W}} 4.820$ October 2011 earthquake: Earth and Planetary Sciences Letters 379, 56-63.

Frohlich C., Walter J.I., Gale J.F.W., 2015. Analysis of Transportable Array (USArray) data shows earthquakes are scarce near injection wells in the Williston Basin, 2008-2011: Seismological Research Letters 86, 492-499.

Gaswirth S.B., Marra K.R., Cook T.A., Charpentier R.R., Gautier D.L., Higley D.K., Klett T.R., Lewan M.D., Lillis P.G., Schenk C.J., Tennyson M.E., Whidden K.J., 2013. Assessment of undiscovered oil resources in the Bakken and Three Forks Formations, Williston Basin Provice, Montana, North Dakota, and South Dakota: USGS Fact Sheet 2013-3013.

Gendzwill D. and Unrau J., 1996. Ground control and seismicity at International Minerals and Chemical (Canada) Global Limited: Canadian Institute of Mining Bulletin 89, 52-61.

Hajnal Z., Nemeth B., Clowes R.M., Ellis R.M., Spence G.D., Burianyk M.J.A., Asudeh I., White D.J., Forsyth D.A., 1997. Mantle involvement in lithospheric collision: Seismic evidence from the Trans-Hudson Orogen, western Canada: Geophysical Research Letters 24, 2079-2082.

Hasegawa H.S., Wetmiller R.J., Gendzwill D.J. 1989. Induced seismicity in mines in Canada - an overview: Pure and Applied Geophysics 129, 423-453.

Horner R.B. and Hasegawa H.S., 1978. The seismotectonics of Southern Saskatchewan: Canadian Journal of Earth Sciences 15, 1341-1355. 
Horton S., 2012. Injection into subsurface aquifers triggers earthquake swarm in Central Arkansas with potential for damaging earthquake: Seismological Research Letters 83, 250-260.

Jimenez Gomez J.A., 2006. Geomechanical performance assessment of $\mathrm{CO}_{2}-$ EOR geological storage projects: Ph.D. Thesis, University of Alberta.

Justinic A.H., Stump B., Hayward C., Frohlich C., 2013. Analysis of the Cleburne, Texas, earthquake sequence from June 2009 to June 2010: Bulletin of the Seismological Society of America 103, 3083-3093.

Kaven J.O., Hickman S.H., McGarr A.F., Ellsworth W.L., 2015. Surface monitoring of microseismicity at the Decatur, Illinois, $\mathrm{CO}_{2}$ sequestration demonstration site: Seismological Research Letters 86, 1096-1101.

Keranen K.M., Savage H.M., Abers G.A., Cochran E.S., 2013. Potentially induced earthquakes in Oklahoma, USA: Links between wastewater injection and the $2011 \mathrm{M}_{\mathrm{W}}$ 5.7 earthquake sequence: Geology 41, 699-702.

Keranen K.M., Weingarten M., Abers G.A., Bekins B.A., Ge S., 2014. Sharp increase in central Oklahoma seismicity since 2008 induced by massive wastewater injection: Science 345, 448-451.

Kim, W-Y., 2013. Induced seismicity associated with fluid injection into a deep well in Youngstown, Ohio: Journal of Geophysical Research 118, 3506-3518.

Lomax A., Michelini A., Curtis A., 2009. Earthquake Location, Direct, Global-Search Methods: Complexity In Encyclopedia of Complexity and System Science 5, Springer, New York, 2449-2473

Lomax A., Satriano C., Vassallo M., 2012. Automatic Picker Developments and Optimization: FilterPicker - a robust broadband picker for real-time seismic monitoring and earthquake early warning: Seismological Research Letters 83, 531-540.

Mavko G., Mukerji T., Dvorkin J., 1992. The Rock Physics Handbook. Cambridge University Press.

McLennan J.D., Hasegawa H.S., Roegiers J.-C., Jessop A.M., 1986. Hydraulic fracturing experiment at the University of Regina Campus: Canadian Geotechnical Journal 23, 548555.

McLellan P.J., Lawrence K.H., Cormier, K.W., 1992. A multiple-zone acid stimulation treatment of a horizontal well, Midale, Saskatchewan: Journal of Canadian Petroleum Technology 31, 71-82.

Morel-à-l'Huissier P., Green A.G., Pike C.J., 1987. Crustal refraction surveys across the Trans-Hudson Orogen/Williston Basin of south central Canada: Journal of Geophysical Research 92, 6403-6420.

Nicholson C., Roeloffs E., Wesson R.L., 1988. The Northeastern Ohio earthquake of 31 January 1986: was it induced? Bulletin of the Seismological Society of America 78, 188217.

Nuttli O.W., 1973. Seismic wave attenuation and magnitude relations for Eastern North America: Journal of Geophysical Research 78, 876-885.

Raleigh C.B., Healy J.H., Bredehoeft J.D., 1976. An experiment in earthquake control at Rangely, Colorado: Science 191, 1230-1237.

Reinbold D.J. and Gillispe M.D., 1974. Seismicity in the area of Ft. Peck, Montana 19661968: Unclassified Final Report AL-74-2 to the U.S. Army Engineer District, Omaha, Nebraska.

Rostron B.J., Whittaker S., Hawkes C., White D., 2012. Characterization. In B. Hitchon (Editor), Best Practices for Validating $\mathrm{CO}_{2}$ Storage, 9-77. Geoscience Publishing, Alberta, Canada. 
Rubinstein J.L., Ellsworth W.L., Mcgarr A., Benz H.M., 2014. The 2001-present induced earthquake sequence in the Raton Basin of Northern New Mexico and Southern Colorado: Bulletin of the Seismological Society of America 104, 2162-2181.

Seeber L., Armbruster J.G., Kim, W-Y., 2004. A fluid-injection-triggered earthquake sequence in Ashtabula, Ohio: implications for seismogenesis in stable continental regions: Bulletin of the Seismological Society of America 94, 76-87.

Stork A.L., Verdon J.P., Kendall J-M., 2015. The microseismic response at the In Salah Carbon Capture and Storage (CCS) site: International Journal of Greenhouse Gas Control 32, 159-171.

Sun A., Gao S.R., Nicot J-P., Lashgari H.R., 2016. Towards establishing a cost-effective plan for long-term monitoring at a $\mathrm{CO}_{2}$-EOR site using static and dynamic data: submitted to IJGGCT, SaskCO2USER Special Issue.

Vilarrasa V. and Carrera J., 2015. Geologic carbon storage is unlikely to trigger large earthquakes and reactivate faults through which $\mathrm{CO}_{2}$ could leak: Proceedings of the National Academy of Sciences 112, 5938-5943.

Verdon J.P., 2014. Significance for secure $\mathrm{CO}_{2}$ storage of earthquakes induced by injection. Environmental Research Letters 9, 064022.

Verdon J.P., Kendall J-M., White D.J., Angus D.A., 2011. Linking microseismic event observations with geomechanical models to minimise the risks of storing $\mathrm{CO}_{2}$ in geological formations: Earth and Planetary Science Letters 305, 143-152.

Verdon J.P., Kendall J-M., Stork A.L., Chadwick R.A., White D.J., Bissell R.C., 2013. Comparison of geomechanical deformation induced by megaton-scale $\mathrm{CO}_{2}$ storage at Sleipner, Weyburn, and In Salah: Proceedings of the National Academy of Sciences 110, E2762-E2771.

Verdon J.P., Stork A.L., Bissell R.C., Bond C.E., Werner M.J., 2015. Simulation of seismic events induced by $\mathrm{CO}_{2}$ injection at In Salah, Algeria: Earth and Planetary Science Letters 426, 118-129.

Williams-Stroud S. and Billingsley R.L., 2010. Techniques to estimate fracture effectiveness when mapping low-magnitude microseismicity: SEG Expanded Abstracts 2010, 20752079.

Wilson W., Surjik D.L., Sawatzky H.B. 1963: Hydrocarbon potential of the South Regina area, Saskatchewan: Saskatchewan Department of Mineral Resources, Report No. 76.

Worth K., White D., Chalaturnyk R., Sorensen J., Hawkes C., Rostron B., Johnson J., Young A. 2014. Aquistore project measurement, monitoring and verification: From concept to $\mathrm{CO}_{2}$ injection: Energy Procedia 63, 3202-3208.

Zoback M.D. and Gorelick S.M., 2012. Earthquake triggering and large-scale geologic storage of carbon dioxide: Proceedings of the National Academy of Sciences 109, 1016410168.

Zoback M.D., and Gorelick S.M., 2015. To prevent earthquake triggering, pressure changes due to $\mathrm{CO}_{2}$ injection need to be limited: Proceedings of the National Academy of Sciences 112 , E4510. 